\title{
Lean Service Approach for Consulting Services Company
}

\author{
Elisa Kusrini $^{1 *}$, Fathia Nisa ${ }^{1}$, Vembri Noor Helia ${ }^{1}$ \\ ${ }^{1}$ Department of Industrial Engineering, \\ Faculty of Industrial Technology, Islamic University of Indonesia, Yogyakarta, 55584, INDONESIA \\ *Corresponding author
}

DOI: https://doi.org/10.30880/ijie.2019.11.05.024

Received 25 April 2019; Accepted 08 September 2019; Available online 10 September 2019

\begin{abstract}
The service industry sector is one of the livelihoods in Indonesia. This sector has increased from year to year. This study aims to identify and determine the amount of dominant waste in consulting service companies based on the concept of lean service and provide recommendations to minimize the occurrence of dominant waste from the causal factors. The results of the identification of waste using the value stream mapping show that there are activities that are non-value-added with a total time of 200.52 minutes of a total time of 839.01 minutes or $23.90 \%$ in the process of public training services. Based on the future state from value stream mapping after processed improvements there was founded that the time of activities that non-value-added reduced by 136.36 minutes, from 839.01 minutes to 702.65 minutes or reduced by $16.25 \%$. The proposed improvements provided based on the analysis of critical waste causes to minimize waste dominant in the form of waste waiting are the addition of new employees for marketing, making Standard Operating Procedure, setting training price standards, and increasing bandwidth to increase internet speed in the work environment.
\end{abstract}

Keywords: Consulting services company, lean service, waste, value stream mapping

\section{Introduction}

Nowadays, the era of globalization has an impact on industries that are growing and developing very rapidly. This is supported by the development of highly dynamic technology. Similarly, Indonesia has made industrial sector as one of the livelihoods of its residents. In developed countries, the development of the service sector actually exceeds the manufacturing and goods industry sector. This shows that the service sector is increasingly needed by humans.

The service industry sector in Indonesia has developed year by year. This sector also has an important role in the economy and employment in one of the provinces in Indonesia, Special Region of Yogyakarta. Based on the calculation of the gross regional domestic product by industrial origin, its contribution to the economy of Special Region of Yogyakarta since 2012-2016 is relatively stable in the range of 2 percent. While the growth rate of the service industry in Special Region of Yogyakarta is always positive with an average growth of 5.20 percent [1].

One of the service industry company in Special Region of Yogyakarta engaged in the field of training, certification, and consultancy services that is incorporated as a limited liability company. This company provides training and consulting services for companies, government institutions, educational institution, non-governmental organizations, and individual in various fields including human resources \& development, business \& management, engineering, oil \& gas, electricity \& energy, information technology, finance, law and others. This company has 4 service products offered, namely public training, in house training, certification, and consultation.

In May 2017 to April 2018, public training services are services that have the highest average number of customer requests, namely 112 requests per month. Whereas in January 2018 to April 2018, it is known that the number of public training service participants is the highest number of participants, namely 31 participants per month. It can be concluded that public training services are the services most often served by the company. Amidst increasingly high 
global competition, companies that engaged in services are required to be able to improve their service quality. Therefore, it is important for the company to improve its quality of services, especially in public training services.

Services strive to continue to seek new and innovative business enhancements and / or process improvement methodologies to reduce costs, escalate quality and productivity and to increase delivery speeds. Lean is one method that can be used to make improvement [2]. According to Gaspersz [3], lean service has the same meaning as lean manufacturing. The difference lies in the concentration of the field of application. Lean service is more focused on service, administration and office products, and while lean manufacturing for goods products. Womack and Jones [4] develop lean principles throughout the organization. Now, lean has been accepted and adopted in all fields. The main principle of lean is to reduce waste. Not only in the manufacturing industry, such as in the car industry, electronics, but also in the project and service industry $[5,6]$. A large number of papers on services using lean have been published in recent years [2].

Vignesh et al. [7] conducted a study that aims to provide insight into how lean service is implemented in various sectors and lean contribution to improving the quality of services provided while reducing costs. This study revealed that lean practices can be successfully implemented in the service sector by generating profits and customer satisfaction.

Studies by Farouk et al. [8] focused on reducing process waiting time by using value stream mapping (VSM). The implementation of this method shows the results that there is a reduction in waiting time for patients in the CT scan process of these outpatients. VSM is also used to procure endovascular stents in hospitals to eliminate waste in nonvalue-added activities [9].

The value stream mapping method in the service line was also carried out in a study conducted by Morlock and Meier [10] which concluded that the value stream mapping service could be successfully implemented in the blueprint service. Lean service principles are also used in other service lines. De Steur et al. [11] conduct a literature review from several studies that implement value stream mapping on agri-food industry. The results of the literature review are that value stream mapping can be used to identify food losses and waste and the use of just-in-time tools and $5 \mathrm{~S}$ can be used as a continuous improvement strategy.

A literature study conducted by Leite and Vieira [12] said that lean does not have a tool model or practice and standards for the service sector. It can be noted that each author uses a "mix" of tools and practices that in their opinion function best in an operation. Furthermore, not only large industries use lean implementation, but also in many Small Medium Enterprise (SME) use it, too [13].

Although many service organizations have successfully adopted the lean methodology, very little amount of research has been carried out on consulting service company.

Through this research, it is expected that the lean service principle can be used to identify waste that occurs in the organization, especially in the consulting service company. In addition, this research is also expected to provide recommendations for the company to minimize the occurrence of waste based on the causes.

\section{Methods}

This research was conducted at one of the service companies in Special Region of Yogyakarta, which is a company in the field of training, certification, and consultancy services located at Sleman, Yogyakarta, indonesia. The object of research in this study is the process of public training services. The study was carried out in a time span starting from March until June 2018. The research variables are type of waste, process cycle time, efficiency rate. This research is carried out in the following steps:

- Identify business process of the service consulting company

- Measure cycle time of each process and construct current state Value Stream mapping

- Identify type of waste for each process.

Waste that occurs in the service business process of public training is identified through interviews with experts from the company and observation of the business processes that occur. From the waste that has been identified, then proceed with identifying the dominant waste through questionnaires to the respondents, the workers at the company. The results of the questionnaire are then processed using the Borda Method to determine which waste has the highest weight and be critical. Hojjati [14] in his paper explained the ranking of 13 lean tools by an integrated SAW, TOPSIS and Borda Method. Sayyida [15] also used the Borda Method to identify the critical waste. So, this research will analyze the waste that occurred at company and identify the critical waste by using Borda Method.

-Analyzing the factors that cause waste to occur using fishbone diagrams.

-Proposed improvements are suggested and develop future state VSM.

\section{Results and Discussion}

\subsection{Business Process of a Service Consulting Company}


Based on direct observation and interviews with training service company employees, a description of the business process is obtained. The business process for public training services can be divided into main operational processes, namely accepting client requests, client follow-up, client confirmation, preparation of training venue, preparing receipts document, invoices and tax invoices, contact instructor, preparing module, training materials and training certificate, preparing training kits and souvenirs, conducting the training, and training fee collection.

\subsection{Current State Value Stream Mapping}

Current state value stream mapping is made based on data that has been collected in the previous stage. Current state value stream mapping from the public training process can be seen in Fig. 1. From the current state value stream mapping in Fig. 1, it was obtained that there are 10 main processes that exist along the flow process of public training services. From the calculations, it is known that there are 930.38 minutes for value added activities, 1057.19 minutes for non-value-added activities, and 69.02 minutes for necessary non-value-added activities from the overall public training service process. Then from the calculation of the percentage of time per activity, it is known that the percentage of time for value added activities is $45.25 \%$, for non-value added activities is $51.39 \%$, and for the non-value added activities is $3.36 \%$.According to Gaspersz [3], the non-value added activity of all activities along the service value stream in the service process chain is a waste. It can be concluded that the percentage of NVA or non-value added in the current state value stream mapping in the public training service process is $51.39 \%$.

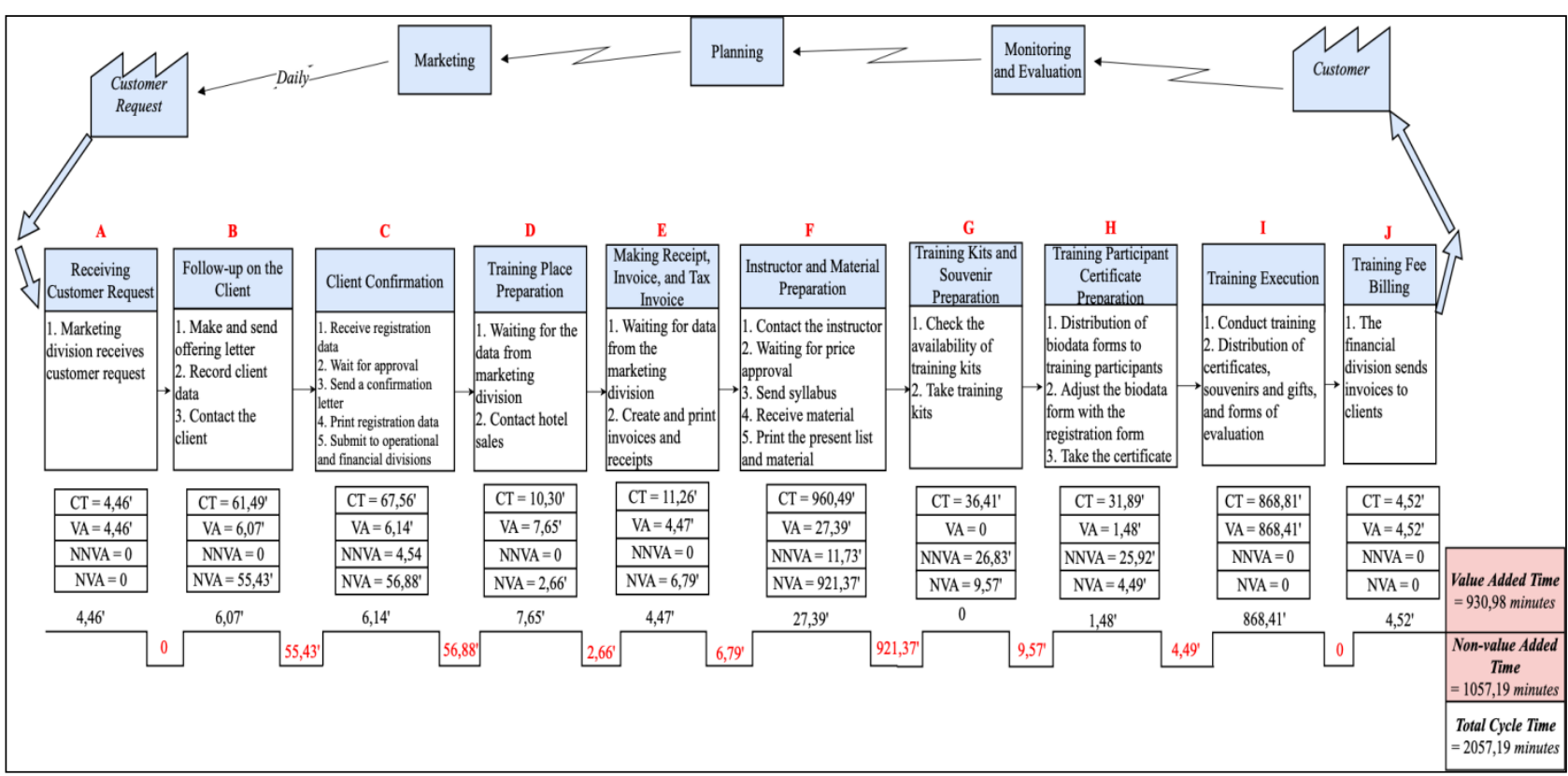

Fig. 1 - Current state value stream mapping.

\subsection{Dominant Waste Analysis}

To identify the critical waste to be minimized, the weighting method is used with the Borda Method to determine which waste is most dominant. The following (Fig 2) is a graph of waste weight ranking based on the calculation results of the Borda Method. 


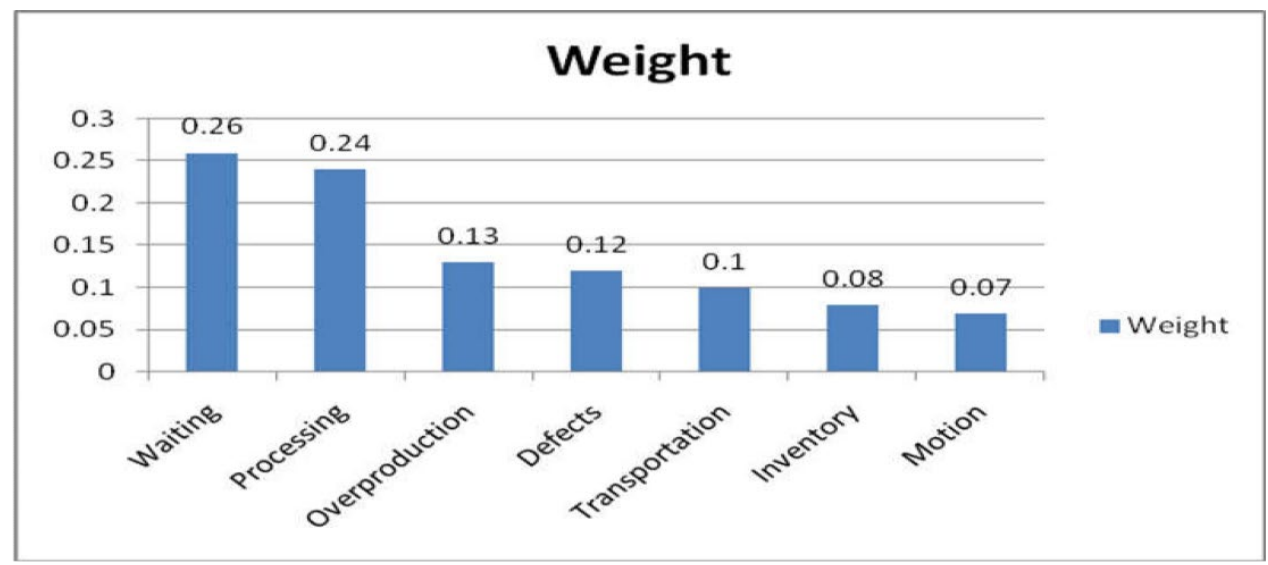

Fig. 2 - Ranking of waste weight.

Based on the graph above, it can be concluded that waiting is the type of waste that most often occurs in the internal business processes of public training services, with a weight of 0.26 . Because the waiting waste has the biggest weight rating, waste waiting requires more attention to be minimized.

The waste waiting that occurs in the public training service process is as follows:

-Delay responds to client requests

-Waiting for the data of the client who has registered

-Waiting for director's approval for prices

\subsection{Analyze the Causes of Dominant Waste with a Fishbone Diagram}

From the results of the identification of the causal factors, the data of the causal factors of waste waiting can be described in the fishbone diagram as depicted on Figure 3a, Figure $3 \mathrm{~b}$ and Figure $3 \mathrm{c}$ as follows. This fishbone diagram is developed through discussion and interviews with experts from the company and observation of the business processes.

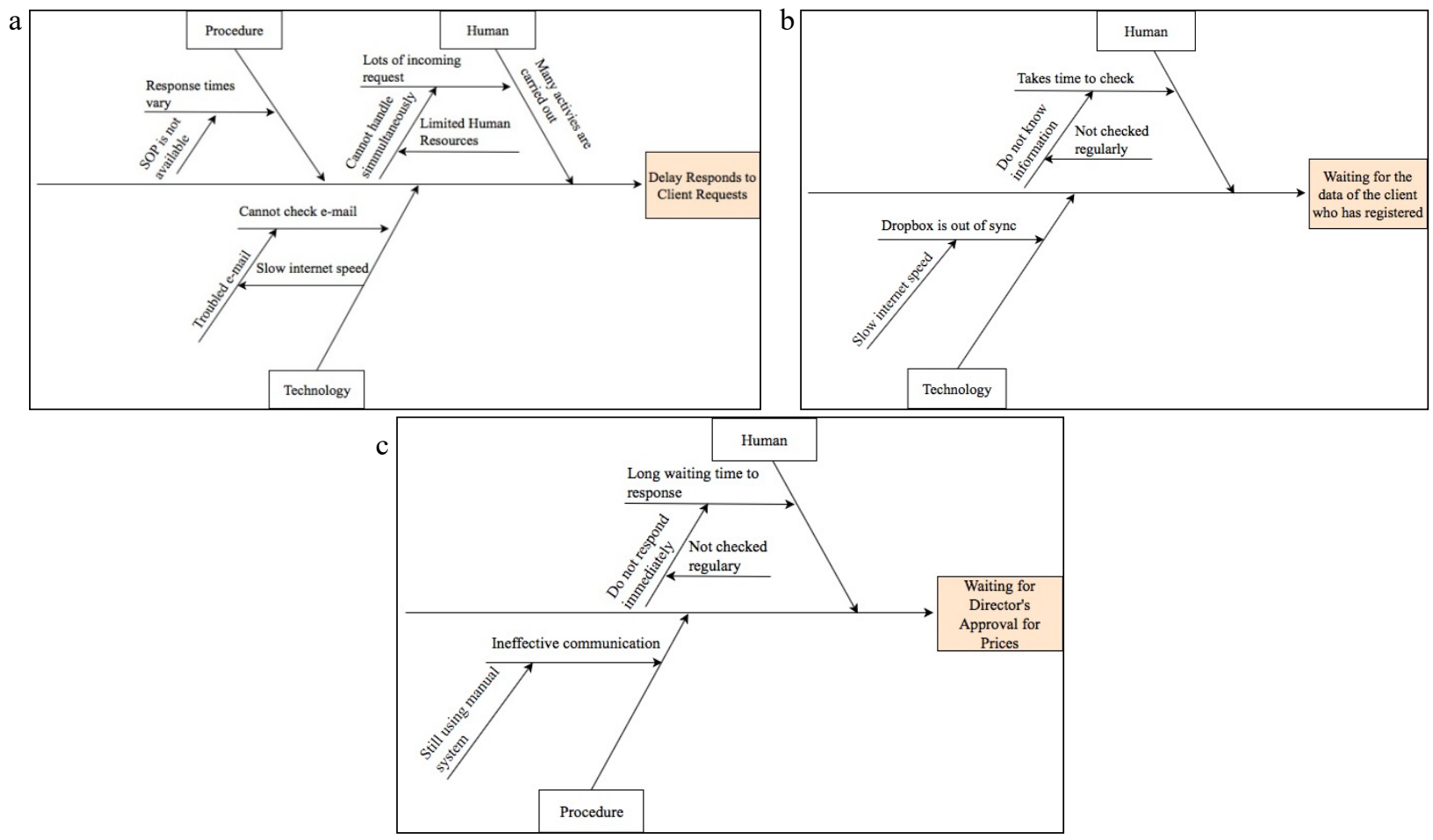

Fig. 1 - (a) Waste waiting fishbone diagram on delay activity responds to client requests; (b) Waste waiting fishbone diagram in the activity awaits the data of the client who has registered; (c) Waste waiting fishbone diagram on activities awaiting director's approval for prices. 


\subsection{Proposed Improvement Based on Analysis of the Causes of Waste}

Based on analysis of cause of waste using fishbone diagram, the following are suggestion for improvement:

-Recruit new employee

Waste waiting in the form of a delay responds to client requests is caused by lack of human resources in the marketing department. By adding human resources, the problem of delaying responding to client requests can be resolved.

-Update SOP

Standard Operating Procedure (SOP) is needed to realize order in a series of activities in a company or organization. In addition, SOP also aims to avoid not doing a good job, workers who are not responsible, negligent and always wrong in their work, and all activities that are not suitable, which will lead to a company / organization taking considerable risks.

-Set standard price

To reduce waste in the form of waiting time to ask for price approval, a minimum standard of price guidelines for employees is proposed. With this guideline, employees do not need to ask for price approval from the director and can make their own decisions by referring to the standard.

-Add bandwidth

Bandwidth is the term used to refer to the value of consumption in the transfer of data used between client and server devices within a certain period of time, which value is calculated in units of bits per second (bps) or bits / seconds. Bandwidth can also be defined as the width or extent of the frequency used by the signal in the transmission medium. It can be concluded that this bandwidth is the maximum capacity of data that can be used to send data in seconds from one communication path. In this case, by increasing the speed of bandwidth it can overcome the problem of internet speed which is slow and inhibits the work so that the work can be done properly.

\subsection{Future State Value Stream Mapping}

The final step is to make future state value stream mapping as depicted on figure 4 . The future state value stream mapping is made based on reduction or minimization of activities that are considered non-value added. Based on the results of data processing, it can be concluded that there are 3 activities that belong to the group of non-value-added activities, namely delay responding to the client, waiting for the approval of the director for the price and waiting for the data of the client who has registered.

In the delay activity responds to the client, namely activity C.2, the activity in the form of waiting for approval can be minimized by the proposed improvement by adding new employees and adding bandwidth. The time of non-valueadded activity can be reduced by setting a standard time to respond for 25.89 minutes. So that non-value-added time can be reduced by 30.99 minutes.

Then, in the activity waiting for the director's approval, namely in activity F.2, the proposed improvements that can be applied to reduce the time of non-value-added activities are by updating the SOP and setting a standard price. The renewal of the SOP was carried out aimed at removing activities requesting the approval of the director. In the future it is expected that the marketing division can make its own pricing decisions based on predetermined price standards. So that a long enough time to request a director's approval can be eliminated. And for the last non-value-added activity, namely the activity of waiting for data on clients who have registered for D.1 activity, this activity can be eliminated by adding bandwidth and updating the SOP. The updated SOP, namely the marketing division does not need to submit data to the operational division. Data can be directly updated via dropbox so that it can eliminate waiting time.

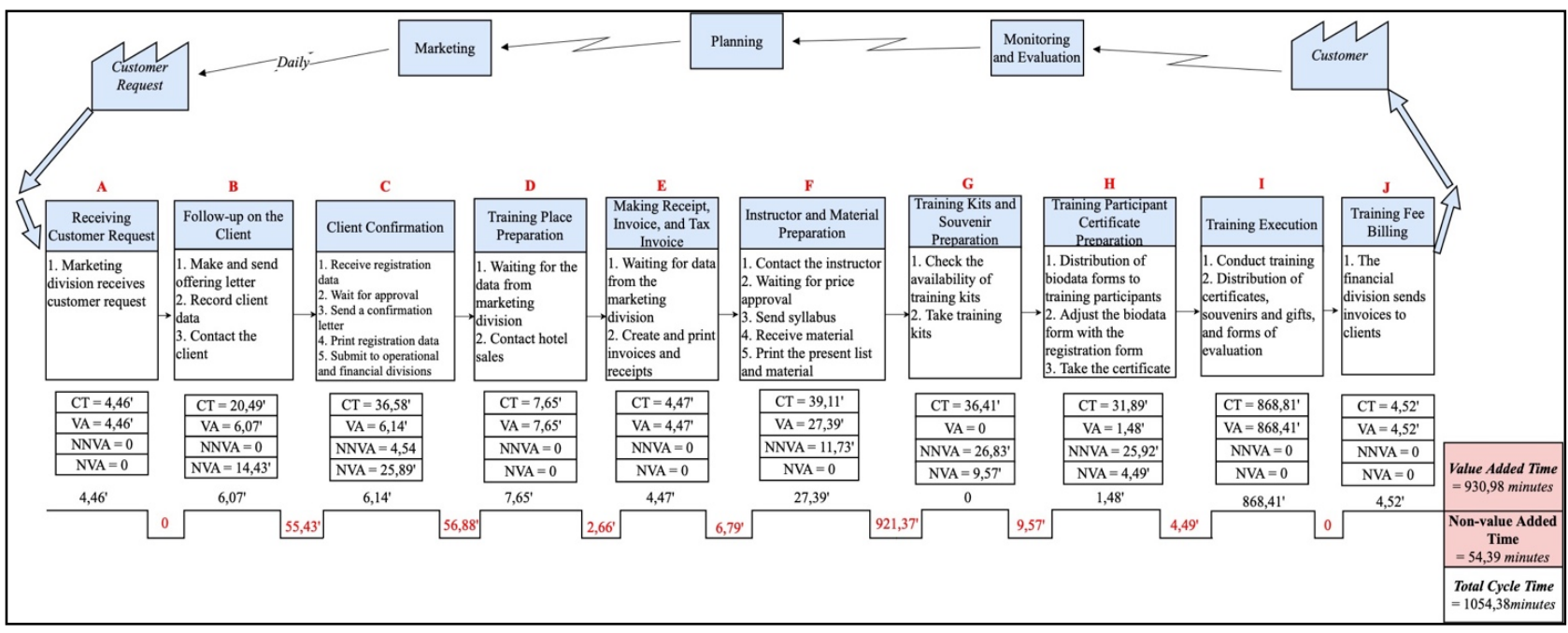


Fig. 4 - Future state value stream mapping.

The comparison of the percentage of value added and non-value-added activities before and after improvements can be shown in the Table 1.

Table 1 - Comparison of percentage of activity before and after improvements

\begin{tabular}{ccccc}
\hline \multirow{2}{*}{ Type of Activity } & \multicolumn{2}{c}{ Current State } & \multicolumn{2}{c}{ Future State } \\
\cline { 2 - 5 } & Time(minutes) & Percentage (\%) & Time(minutes) & Percentage (\%) \\
\hline VA & 562,20 & 67,01 & 562,20 & 80,01 \\
NVA & 200,52 & 23,90 & 64,16 & 9,13 \\
NNVA & 76,29 & 9,09 & 76,29 & 10,86 \\
\hline Total & 839,01 & 100,00 & 702,65 & 100,00 \\
\hline
\end{tabular}

After making improvements, the value of non-value-added activities decreased by 136.36 minutes from 200.52 minutes to 64.16 minutes or decreased by $68.01 \%$. The total cycle time also decreased by 136.36 minutes, from 839.01 minutes to 702.65 minutes or reduced by $16.25 \%$. The result of future state value stream mapping based on the proposed improvements can be seen in the Fig. 4. Another method for reducing waiting time is by analyzing queues using queuing theory which can increase production or service [16]. This method can be a research opportunity to reduce waiting time.

\section{Conclusion and Proposed Improvements}

Based on the results of the identification of the waste produced and interviews, it was found that there were six types of waste that occurred in public training service process, namely movement, inventory, processing, waiting, transportation, overproduction, and defects with the amount of time wasted by non-value added activities is 200.52 minutes of the total time of 839.01 minutes or $23.90 \%$ of the total time of the public training processes. The proposed improvements provided based on the analysis of critical waste causes to minimize waste dominant in the form of waste waiting are the addition of new employees for marketing, making SOPs, setting training price standards, and increasing bandwidth to increase internet speed in the work environment. So, based on the future state value stream mapping after processed improvements there were a total reduction of cycle time as many as 136.36 minutes, from 839.01 minutes to 702.65 minutes or reduced at $16.25 \%$ and a reduction in the total non-value added time by 136.36 minutes from 200.52 minutes to 64.16 minutes or a decrease of $68.01 \%$.

\section{Acknowledgement}

The authors would like to acknowledge to PT Expertindo Yogyakarta that has allowed us to conduct research on its public training service.

\section{References}

[1] BPS-Statistics of D.I. Yogyakarta Province, Gross Regional Domestic Product of Daerah Istimewa Yogyakarta Province by Industrial Origin 2012-2016. Yogyakarta: BPS-Statistics of D.I. Yogyakarta Province, 2017.

[2] S. Gupta and M. Sharma (2018). Empirical analysis of existing lean service frameworks in a developing economy. Int. J. Lean Six Sigma, doi:10.1108/ IJLSS-03-2016-0013.

[3] V. Gaspersz (2006). Continuous Cost Reduction Through Lean-Sigma Approach, Jakarta: GramediaPustaka Utama, 2.

[4] J. P. Womack and D. T. Jones (1996). Lean Thinking: Banish Waste and Create Wealth in your Organisation, London: Simon \& Schuster.

[5] Sasitharan Nagapan et al., (2012). Identifying Causes of Construction Waste - Case of Central Region of Peninsula Malaysia, International Journal of Integrated Engineering, Vol. 4 No. 2 (2012) p. 22-28.

[6] Shivaraj Subramaniam et al., (2018), Investigate How Construction Waste Generation Rate Is Different for Every Types of Project in Peninsular Malaysia Using Site Visit Method, International Journal of Integrated Engineering, Vol. 10 No. 1 (2018) p. 150-156.

[7] V. Vignesh, M. Suresh, and S. Aramvalarthan (2016). Lean in service industries: A literature review. IOP Conf. Ser. Mater. Sci. Eng., 149(1), doi:10.1088/1757-899X/149/1/012008.

[8] F. Dako et al., (2018). Use of Value Stream Mapping to Reduce Outpatient CT Scan Wait Times. J. Am. Coll. Radiol., 15(1), 82-85.

[9] U.K.Teichgräber, M. de Bucourt, M. (2012). Applying value stream mapping techniques to eliminate non-valueadded waste for the procurement of endovascular stents. European Journal of Radiology, 81(1), e47-e52. 
[10] F. Morlock and H. Meier (2015). Service Value Stream Mapping in industrial product-service system Performance Management. Procedia CIRP, 30, 457-461.

[11] H. De Steur, J. Wesana, M. K. Dora, D. Pearce, and X. Gellynck (2016). Applying Value Stream Mapping to reduce food losses and wastes in supply chains: A systematic review. Waste Manag., 58, 359-368.

[12] H. dos R. Leite and G. E. Vieira (2015). Lean philosophy and its applications in the service industry: a review of the current knowledge. Production.

[13] A. Alkhoraif, H. Rashid, P. McLaughlin (2018). Lean Implementation in small and medium enterprises: Literature review. Oper. Res. Perspect., 100089.

[14] S. M. Hossein Hojjati and A. Anvary (2013). An integrated SAW, TOPSIS method for ranking the major lean practices based on four attributes. World Appl. Sci. J., 28(11), 1862-1871.

[15] G. Sayyida, F. Fahma, and I. Iftadi (2018). Process Improvement in Outpatient Installation RSUD dr. Soediran Mangun Sumarso Using Lean Hospital Approach. IOP Conf. Ser. Mater. Sci. Eng., 319(1).

[16] Marsudi, M., (2012). Application of Queuing Theory in Analyzing the Use of Production Capacity, International Journal of Integrated Engineering (IJIE), Issue on Mechanical, Materials and Manufacturing Engineering, Vol 2 no 1 . 